\title{
CONTENT ANALYSIS OF NEW MEANS OF COMMUNICATION IN CONTEMPORARY DEMOCRATIC STATES
}

\author{
Mihaela Rusu ${ }^{1}$
}

\begin{abstract}
The previous period of United States presidential elections of 1996 has redirected the relevant scientific research to investigate the correlation online communication - political sphere. Consequently were formulated various paradigms and the most discussed was the democratic paradigm, according to which the representation serve as a basic principle of modern democracy. The study of the level of influence of new communication technologies on political sphere became, for a number of scientific investigations carried out in USA, Canada and later in some European countries such as France, Italy, the UK (in 2000 and since 2007 in Romania), an important objective of empirical research. In most cases, the first stage of the investigation of online political communication has been marked by some methodological problems such as: the changeable nature of web space, the necessity to elaborate new indicators able to represent basic aspects of studied reality, the temporal validity of the data. The elaboration of A Model of Cyber-Interactivity by Sally J. McMillan has contributed to overcome these difficulties and has demonstrated the effectiveness of content analysis as research method used for the study of Web Space dynamic reality. Later, the research team from the University of Rochester (Paul Ferber, Frantz Foltz, Rudy Pugliese) have perfected the two-way interactivity model (elaborated by Sally J. McMillan) and have it completed with three-dimensional model of interactivity for the purpose of quantitative investigation of political websites and to argue that these forms of new media correspond to the ideals of cyberdemocracy.
\end{abstract}

Key words: content analysis, research method, online communication, political sphere, interactivity, democracy.

The elaboration of models and the formulation of theories of new media were, in most cases, a research process marked by some methodological difficulties. As mentioned by Benjamin Barber, the fluctuating nature of web space is the main disadvantage for the empirical and quantitative approach of new media. In the opinion of Steven Jones, the investigation of online environment is a real provocation for researchers in the field of human sciences. The author of the book Doing Internet Research has described the web space as changing environment and ephemeral information flow. The same methodological problems were identified by Rosanna De Rosa and presented as theses at one of the Annual Conferences of Italian Political Science Association (September 2000, Naples). In his opinion, the period preceding the United States presidential election of 1996 has reoriented the scientific research to investigate the correlation online communication - political sphere. Consequently were formulated various paradigms, but the most discussed was the paradigm of democratic representation, according to which the representation serve as a basic principle of modern democracy. The trend of change of emphasis from representation to participation, remarked in the recent years, was conditioned by the development and the increased application of new

\footnotetext{
${ }^{1} \mathrm{PhD}$ Student, Consultant at the Department of Policies in Science and Innovation Sphere, Academy of Sciences of Moldova, rusumihaela564@gmail.com
} 
communication and information technologies. In this sense, the interaction between the Internet and the political sphere corresponds with hypermediation process of public sphere and high level of receiver control in the online environment.

All these changes were taken into account by scientific community, focused, in the future, on the argumentation of the hypothesis that new media have influenced the field of political communication. So, the study of the level of influence of new communication technologies on political sphere became, for a number of scientific investigations carried out in USA, Canada and later in some European countries such as France, Italy, the UK (in 2000 and since 2007 in Romania), an important objective of empirical research. New indicators able to represent basic aspects of studied reality, new elements of evaluation of the information flow and the temporal validity of the data (for a period of max. 3 months) were the main methodological problems that marked the debut period of scientific investigations in the field of online political communication. A first attempt of classification of scientific publications in the field, as specified by Rosanna De Rosa, allows emphasizing three main types of analytical approaches of new communication technologies. In this context, the structural approach is described as investigation of main technical characteristics of websites, conducted to determine the functionality of the studied units in the communication process. The level of navigation on the website, the interactivity and personalization can be evaluated as a result of meticulous examination of structural components of these forms of new media, including: the number of pages, the quantity of information units and items classification, the presence of elements of interactive communication. For the researchers who opt for the second type of analytical investigation, named rhetorical approach, it is important to study "what is communicated, but especially how we communicate" [2, p. 199]. In this case, the contents of websites are examined under the following units of analysis: form, style, language, theme, significance. The third type of theoretical investigation - the socio-cultural approach is based on the study of new media as integral parts of a complex social process. It is obligatory for such scientific investigations not only understanding the phenomenon itself, but also the delimitation of certain contextual characteristics. As an example can be, in this case, the analysis of political websites used by candidates during the pre-election period, which sums up not only the examination of contents posted on these online communication platforms, but also the competitiveness of political actors, the dialogue that they have with their opponents or messages sent via the traditional media. Another good example of socio-cultural approach of new media is theoretical and practical study of web space density, research conducted by Pippa Norris in 2001. The analysis of web sites of political parties and governments from different countries was conducted under the following variables: the level of socio-economic development of the country, the degree of democratization, the type of political system, the information system functionality. The results demonstrated the tendency of technological innovation implementation to a higher level in the case of representative political institutions unlike studied political parties. Also, it was established that the utilization rate of new media as a channel for political information depends on the level of economic development of each country [6].

As a result of the analysis of 19 publications in the field of communication sciences, Sally J. McMillan concluded that the web space is a flexible reality, but it can be scientifically investigated. The content analysis is, according to the conclusions made on the basis of this theoretical study, the most appropriate approach to dynamic reality that represents the web space. The unique problems that may occur in the case of empirical investigation of online communication are the rapid development of websites and continuous exchange of contents in digital space. However, this method allowed at that stage (the early 2000s), studying the following three themes: diversity, marketing and use of new communication and information technologies. 
Aiming to develop recommendations for the use of this method for studying online communication process, Sally J. McMillan considered useful to find answers to the following main questions: 1. How were readapted content analysis principles to this emerging form of communication from virtual environment? 2. What are the main problems of application of this method for researching the Web?

In brief presentations of the notional evolution of content analysis were mentioned Krippendorff, Berelson, Lazarsfeld - those who formulated in theory and demonstrated in practice the advantages of this method of research. Citing Krippendorff, the author of that paper defines four opportunities offered by this method: 1 . is discreet, 2 . can be used when the research subject is the unstructured material, 3. take account of context, 4 . has the capacity of processing a large volume of data. In his opinion, the possibility of examining a large volume of data is the main advantage "in terms of Web analysis" [5, p. 81].

According to the recommendations made by Sally J. McMillan, concerning the future research in the field of new media communication, the content analysis is an effective method of scientific investigation, but only with respect of two basic principles:

1. are followed the five steps - key for applying this method:
a) defining theme / working hypotheses,
b) identification of the material for analysis (sample selection)
c) establishing units of analysis,
d) data collection and data processing,
e) analysis of the results.

2. are examined the defining particularities of new media: multidirectional dissemination of contents, continuous flow of information over long distances, hypertextuality, interactive communication options.

In this context, the specialists in the field noted that political websites - first forms of new media applied to facilitate the dialogue between the government and the governed, are continuously updated and readapted to information needs of users. Mainly integrated in pre-election communication strategy of the states with high development level (US, Canada, UK, Italy, France), the static websites (as booklets) served for the rapid transfer of information to a large number of people and for the increased unidirectional communication. The new age of online political communication has been marked by the development of Web 2.0, the emergence and use of blogs, social networks, microblogging systems and the dissemination of information in audio and video file formats. The interactivity is the basic characteristic of new emerging media forms as a result of using Web 2.0 techniques. This feature of new media allows the conversation between two or more persons in the online environment and in the case of political communication - the direct dialogue between politicians and citizens. Therefore, occurs the exceeding of limits of the unidirectional communication, asymmetric, specific for traditional media and is going on the democratization of political dialogue thanks to new mechanisms for the active involvement of citizens in decision making process. The integration of new media in the communication strategy of political actors, 
both during the election period and the period of exercise of political power, are effective tools for the mobilization of electorate and to increase the credibility of the voters. Direct and transparent dialogue, the trend of personalization of the political discourse and to overcome the inefficiencies of previous message, especially observed in the case of presidential and parliamentary communication, are the guarantee of political capital for leaders and functional optimization of representative institutions.

As mentioned by John C. Tedesco, the study of the application of new media in political communication has contributed to the diversification of problems and, consequently, to the renovation of research methods [7]. Following the example of Wimmer and Dominick, the American researcher delimits, in the basis of the criterion the thematic of the research, the next four steps:

1. defining characteristics of the new medium of communication (investigation period of the advantages of using NTC by political leaders and representative institutions, are mentioned: Selnow, Barber, Sparks etc.);

2. analysis of the use and users of new media (includes: the study of new environment as digital device, the investigation of political candidates websites and of the correlation Internet politics - public sphere, are mentioned Bennett and Entman who argued the thesis concerning the ideal emergence of a public sphere devoid of political constraints on receiving information, Blimber who predicted that the Internet will become a system of hyperpluralism, Gamson who studied the importance of public discourse for the development of democracy etc.);

3. determining the effects of new media (in this thematic compartment are mentioned the results obtained by researchers who have investigated the structural obstacles of the Internet (Entman, Barber, Gandi), the civic engagement (Garramone, Gamson) or political mobilization (Norris, Sparks, Keane), the new generation of the Information Society (Putnam, Delli Carpini) and the credibility of information posted online (Whillock, Glas));

4. the approach of investigation perspectives of online political communication.

In the description of step 4 are listed the main results of American experts, presented in various reports in the years 1996-2001, and most important scientific publications that contain recommendations and suggestions on new media research methodology. As an example, in the first case, is mentioned the project Congress Online, focused on the complex investigation of 605 political websites and ended with the presentation of a detailed report in 2002. For the investigation of politicians' online communication platforms it was applied a mixed method, derived from a combination of the following processes: focus groups, interviews, public opinion poll, qualitative and quantitative analysis of key structural elements of political websites. According to the analysis of final results, the following conclusions have been formulated: websites are used mostly for the promotion of politicians; online information disseminated in this way is not as expected by users; this situation can be improved if you take into account the five elements that serve to determine the effectiveness of online communication: the public, the information disseminated to citizens, the interactivity, the level of use, the innovation.

The scientific papers of Sally J. McMillan (Professor at the University of Tennessee Knoxville) were appreciated for the complex approach concerning the application of content analysis in the 
case of web space investigation. Based on the analysis of 108 websites, the elaboration of the Model of Cyber-Interactivity has demonstrated the use of this method and served to formulate some important answers on multi-structural nature of the current online communication. According to this model, presented by Sally J. McMillan in 2002, in the paper Four-Part Model A work of CyberInteractivity: Some Places That and More Interactive Others, the communication through new media can have four representations for each of the three main types of interactivity and may vary depending on the level of receiver control. The sender, the receiver and participants are key elements of this model and serve to describe the different roles that individuals have in the process of one-way and two-way communication. The high level of receiver control is possible for the interactivity of category user-to-user, in the case of unidirectional or bidirectional information flow, the achievement of feed-back or mutual discourse. The monologue and the responsive dialogue are indicators of low level of receiver control in the case of the same type of interactivity [4]. The research team from the University of Rochester: Paul Ferber, Frantz Foltz, Rudy Pugliese have perfected the two-way interactivity model (elaborated by Sally J. McMillan) and have applied it to determine "political Web sites' progress toward the ideals of cyberdemocracy" [3, p. 391]. The SixPart Model of Cyber-Interactivity has maintained the same graphic elements used previously to describe the process of online communication and took over the two key concepts: level of receiver control and direction of communication. To describe the mechanism of public deliberation, they formulated the concept three-way communication, which defines the exchange of information, where the third party has the role of knowledge and conferring of a surplus of transparency by publishing message. In this case, the level of receiver control is low if the message is influenced by the source and we have high level of receiver control when communication is made in form of public discourse. The content analysis of 50 political websites, by quantification of its interactive elements, conducted by Ferber and his colleagues, argued the thesis according to which only online platforms of two-way and three-way communication can contribute to the achievement of public deliberation and democratic dialogue [3].

By definition, the presidential communication is formulated as the dissemination, by the president or the presidential institution, of the public or national interest information. The president's interventions as the symbolic leader of a nation, most often, are decoded by the public as special moments. These addresses to the citizens, in the form of speeches, are usually made on special occasions: political ceremonies, crisis situations or major governmental actions. The sober style, ritualized, established by tradition, is specific to this type of institutional political communication.

At present, the new media are important means of optimization of presidential political communication, able to modify the solemn speech, giving it a surplus of veracity and realism. In this sense, we note that the majority of chiefs of democratic states have a personal website and an official website. Unlike other forms of new media (Facebook, Twitter, YouTube, etc.), these online communication platforms have the highest degree of applicability, contributing to political speech personalization and media coverage of presidential action. Content analysis method, applied by the researchers of the University of Rochester (Paul Ferber, Frantz Foltz, Rudy Pugliese), was appreciated and taken up by different researchers in order to determine the effectiveness of political communication. This method consists in quantification of interactive features of investigated new media, analysis of elements involved in online communication process, determination of the level of receiver control. Therefore, the development of a grid for analyzing personal or official websites of Presidents would require the identification and quantification of important elements for the promotion and visualization of political activity such as: information indicators and interactivity indicators. The category of information indicators corresponds to the unidirectional dissemination of messages from political actor to citizens, being considered "use of the Web by top-down scheme" 
$[1$, p. 213]. One of the main features of the informational content is that these messages can be disseminated not only online, but also through traditional media (newspapers, radio, TV). Usually these elements that serve to the achievement of asymmetric communication include (in the case of Presidents' websites): information about the President, the presidential institution or the country that he represents, political leader activity data, slogan, fragments of speeches, the agenda of events, press releases, photo gallery, external links. The list of interactivity indicators includes a number of items that contribute to the establishment of public deliberation. These elements are derivatives of the new options of Web 2.0 technologies, contribute to the achievement of two-way and three-way communication, allow for Internet users to be in the direct dialogue with political leaders: they can ask questions online and receive answers, to express their opinions or participate in debates on specific topics. Following the example of Ferber and his colleagues, on these political websites can be determined the following indicators of interactivity: functional e-mail to political leader or contact forms, active e-mail or contact forms of the staff of presidential institution, site search engine, e-subscription, virtual tours or educational material, online surveys, public forums.

The official websites, Facebook pages, Twitter, YouTube, are the main forms of new media currently applied in governmental communication process of the most European democratic states. These new means of communication and information serve to visualize the activity of government, increase the level of political participation of citizens and contribute to the promotion of electronic democracy. As objects of some researches carried out with the application of quantitative method content analysis, the websites of governments can be evaluated in terms of compliance of representative institution at two basic principles of effective functioning: the representativity and the accountability. The list of information indicators will include in analysis grid the following contents: government program, plan of actions, agenda of events, informative notes on the main activities of the Prime Minister, links to official websites of ministries, extracts of minutes of government meetings, press releases on the activity of the Prime Minister, ministers, members of the government, reports and statistical information. The complex analysis of technological aspects of the official website of this representative institution involves determining the applicable structural elements to achieve direct dialogue between political leaders and citizens such as: e-mail address of the Prime Minister, ministers, members of the government, or contact forms to government communicators, public forums, online surveys, links to Facebook pages, Twitter.

In the case of the investigation of governments' official websites or of online communication platforms, created by the representatives of this institution in order to conduct projects aimed at increasing the level of political participation of citizens, it is advisable to take into account the theoretical and practical value of the concept e-democracy. Transparency and access to information, partnership and public deliberation of some major problems are the main objectives of electronic democracy. The procedure of online consultation with civil society before approving a series of normative acts, drafts of laws, proposals for government decisions, public policy proposals, etc. is an example of successful implementation of e-Government Project and its objectives thanks to the integration of new media in the process of government communication.

The investigations carried out by the Inter-Parliamentary Union experts and the results presented in various reports confirmed the thesis of using the new media as renovation means of parliamentary political communication. According to statistics, in 2000 approximately $1 / 2$ of total legislatives across the world had an official website, used for the purpose of rapid distribution of the information regarding the activity of drafting and approving law, in order to respect the basic principles of these representative institutions (representation, accountability, transparency) and for effective communication with citizens. The contrastive analysis of 125 websites of national 
legislative institutions, carried out by the IPU's experts, demonstrated the presence of similar structural elements and the trend of compliance of these online communication platforms to a standard model of political website. These websites contained a multitude of contents about legislative institution, on its structure and activity, tools to facilitate the access to information (sitemap, search engine, information in international languages, section News), interactive communication elements that help achieve bidirectional communication between political leaders and citizens and contribute to consolidating the good image of democratic institutions in the $21^{\text {st }}$ century. Content analysis of these online communication platforms can be useful for studying the evolution of these forms of new media and their applicability in the context of parliamentary political communication. The main items recommended to be included in the list of information indicators are: information regarding the parliamentary system and the structure of legislative institutions, data about the Speaker of Parliament and Vice-Presidents, the list of Members of Parliament, information on parliamentary or electoral system, the full text of the Constitution, agenda of the parliamentary sessions, information about legislative, budget and oversight activities, information on decisional transparency. The list of interactivity indicators includes the main structural elements of the website that allow the direct dialogue between politicians and citizens: online services to send messages (MailTo), e-mail addresses of parliamentarians, external links to the official websites of central public authorities and those of major international parliamentary organizations.

A first analysis of the main forms of new media used by European parliamentarians in the political communication process allows us to conclude that blogs, social networking sites and microblogging systems are used, first of all, for the rapid information and for the knowledge of public opinion. The investigation of these types of online communication platforms requires the determination and quantification of a series of visual, discursive, audiovisual elements. For example, the analysis grid of a Facebook page may include the following indicators: quantity, thematic and frequency of posted messages, audience share, expressed by the number of likes, presence and significance of visual (audiovisual) elements, the level of interactivity (calculated in accordance with the quantity of forwarded messages, the number of likes and comments).

The analysis of main forms of new media integrated in communication strategy of Moldovan parliamentarians allows us to note that Facebook and Twitter are the most popular and frequently used. These online communication platforms were appreciated for the possibility of posting concise messages and for the rapid flow of information. In 2016, Marian Lupu and Mihai Ghimpu were the most active users of new media and Iurie Leanca is recognized as Moldovan politician with the largest audience in the online environment.

Facebook page of Iurie Leanca, the actual President of European People's Party of Moldova, was created in 2013, contains a variety of discursive and visual elements used effectively in order to consolidate the image of the politician and is appreciated by 45985 persons. The rubric information includes: data on marital status and regarding the activity of political leader, his biography and the welcome message on his Twitter account, a link to the official website of the European People's Party of Moldova. Despite the large number of posted contents, the video (posted on November 27, 2014, with a total of 111519 views) is the unique element of personalization of his political discourse. There the political leader participate at the interpretation of the song A new day, a new life - musical work that, in his opinion, serves to expressing the pro-European position of Moldovan young people. Messages posted on the wall of this Facebook page are made by the person I singular, sometimes contain links to primary sources of information or video fragments. Unlike other political actors that intervene with answers to some user comments, the communication 
strategy of Mr. Iurie Leanca is focused on providing timely the information on the most recent political events. We observe, in this case, that the posted messages are similar to informative notes and serve as a theme for public debates.

\section{References}

[1] BASTIEN, FR., GREFFET, F. : Les campagnes électorales à l'ère d'Internet: une comparaison des sites partisanes en France et au Québec. In: Hermès 54. Paris: CNRS Editions, 2009.

[2] DE ROSA, R.: Fra comunicazione e politica. Gli spazi virtuali della democrazia che cambia. In: Domenico Frungillo. La transizione incerta. Vol. 5, Avellino: Studi Meridionali, 2001.

[3] FERBER, P., FOLTZ, FR. and PUGLIESE, R.: Cyberdemocracy and Online Politics: A New Model of Interactivity. In: Bulletin of Science, Technology \& Society, 2007.

[4] MCMILLAN, S. J.: A Four-Part Model of Cyber-Interactivity: Some Places and More Interactive that Others. In: New Media and Society, 2002.

[5] MCMILLAN, S. J.: The Microscope and the Moving Target: The Challenge of Applying of Content Analysis to the World Wide Web. In: Journalism \& Mass Communication, Vol. 77. No. 1, 2000.

[6] NORRIS, P.: Digital Divide: Civic Engagement, Information Poverty and the Internet Worldwide. Cambridge: Cambridge University Press, 2001.

[7] TEDESCO, J. C.: Changing the Channel: Use of the Internet for Communicating about Politics. In: Handbook of political communication research. Mahwah, New Jersey: Lawrence Erlbaum Associated, 2004. 